NBER WORKING PAPER SERIES

\title{
LAND MISALLOCATION AND PRODUCTIVITY
}

\author{
Chaoran Chen \\ Diego Restuccia \\ Raul Santaeulalia-Llopis \\ Working Paper 23128 \\ http://www.nber.org/papers/w23128 \\ NATIONAL BUREAU OF ECONOMIC RESEARCH \\ 1050 Massachusetts Avenue \\ Cambridge, MA 02138 \\ February 2017, Revised March 2022
}

For helpful comments we thank Aslihan Arslan, Nadege Azebaze, Fancesco Caselli, Leandro De Magalhaes, Matthias Doepke, Pascaline Dupas, Chang-Tai Hsieh, Chad Jones, Joe Kaboski, Pete Klenow, Evelyn Korn, Per Krusell, Rody Manuelli, Virgiliu Midrigan, Andrew Newman, Chris Pissarides, Nancy Qian, José-Víctor Ríos-Rull, Richard Rogerson, Paul Romer, Nancy Stokey, Kjetil Storesletten, Kei-Mu Yi, and seminar participants at numerous institutions. All remaining errors are our own. Restuccia gratefully acknowledges the financial support from the Canadian Research Chairs program, the Social Sciences and Humanities Research Council of Canada, and the Bank of Canada Fellowship. Santaeulàlia-Llopis gratefully thanks the Spanish Ministry of Economy and Competitiveness, through the Proyectos I+D+i 2019 Retos Investigacion PID2019-110684RB-I00 Grant, "Europa Excelencia" EUR2021-122011 and the Severo Ochoa Programme for Centres of Excellence in R\&D (CEX2019-000915-S). The views expressed herein are not necessarily those of the Bank of Canada or the National Bureau of Economic Research and are the authors alone.

NBER working papers are circulated for discussion and comment purposes. They have not been peer-reviewed or been subject to the review by the NBER Board of Directors that accompanies official NBER publications.

(C) 2017 by Chaoran Chen, Diego Restuccia, and Raul Santaeulalia-Llopis. All rights reserved. Short sections of text, not to exceed two paragraphs, may be quoted without explicit permission provided that full credit, including $\odot$ notice, is given to the source. 
Land Misallocation and Productivity

Chaoran Chen, Diego Restuccia, and Raul Santaeulalia-Llopis

NBER Working Paper No. 23128

February 2017, Revised March 2022

JEL No. O1,O4,O55

\begin{abstract}
Using detailed household-level data from Malawi on physical quantities of outputs and inputs in agricultural production, we measure total factor productivity (TFP) for farms controlling for land quality, rain, and other transitory shocks. We find that operated land size and capital are essentially unrelated to farm TFP implying substantial factor misallocation. The agricultural output gain from a reallocation of factors to their efficient use among existing farmers is a factor of 2.8-fold nationwide and 1.8-fold within enumeration areas, the narrowest geographical category in our data. Constructing a panel to estimate household-farm productivity that controls for transitory variation such as potential measurement error, the agricultural output gain is still quite substantial, between 1.7 to 2.0 -fold, while the pattern of misallocation of near zero correlation of inputs and productivity remains essentially the same. We also provide suggestive evidence of the connection between misallocation and land markets and illustrate how an efficient allocation can substantially reduce agricultural income inequality and poverty.

Chaoran Chen

York University

4700 Keele St.

Toronto, ON M3J 1P3

Canada

chenecon@yorku.ca

Diego Restuccia

Department of Economics

University of Toronto

150 St. George Street

Toronto, ON M5S 3G7

CANADA

and NBER

diego.restuccia@utoronto.ca

Raul Santaeulalia-Llopis

MOVE, UAB, and Barcelona GSE

Plaza Civica s/n

Bellaterra, Barcelona

08193

Spain

rauls@movebarcelona.eu
\end{abstract}

A online appendix is available at http://www.nber.org/data-appendix/w23128 


\section{Introduction}

A fundamental question in the field of economic growth and development is why some countries are rich and others poor. The literature has offered many useful perspectives but we build on two. First, agriculture matters for aggregate outcomes because poor countries are substantially less productive in agriculture compared to rich countries and as a result allocate most of their labor to agriculture (Gollin et al., 2002; Restuccia et al., 2008). Second, misallocation of factors across heterogeneous production units is important in accounting for differences in measured productivity across countries (Restuccia and Rogerson, 2008; Hsieh and Klenow, 2009). We exploit a unique micro-level data from Malawi to measure total factor productivity (TFP) in farms controlling for land quality and transitory shocks. Our main finding is that operated land size and capital are essentially unrelated to farm TFP, evidence of substantial misallocation in the agricultural sector. Quantitatively, misallocation has a substantial negative effect on agricultural productivity, a 2.8fold output gain from an efficient reallocation in the cross-section and between 1.7 to 2.0 -fold in the panel sample that controls for transitory variation and potential measurement error.

Malawi represents an interesting case to study for several reasons. First, Malawi is an extremely poor country in Africa, featuring very low agricultural productivity, a large share of employment in agriculture, and extremely low farm operational scales. Second, the land market in Malawi is largely underdeveloped. Most of land in Malawi is customary and user rights are allocated locally by village chiefs. In our representative sample, more than 84 percent of household farms do not operate any marketed land (either purchased or rented-in). In Malawi, the vast majority of land is either directly or indirectly distributed by the village head. The Customary Land Act grants local leaders power over land transactions such as inheritance and to resolve disputes related to land limits (Kishindo, 2011; Morris, 2016) and this status quo has remained stable since colonial times (Pachai, 1973). Third, there is detailed and high-quality micro data for Malawi allowing us to construct reasonably good measures of household-farm productivity to assess factor misallocation 
in agriculture.

The main data source is the 2010/11 Integrated Survey of Agriculture (ISA) for Malawi collected by the World Bank. This is a large nationally-representative sample of more than 12 thousand households. We also exploit more recent waves of the data to construct a panel of household farms and provide robust results. Whereas the dispersion in our measure of farm-level TFP is quantitatively similar to previous studies in other sectors and countries, our main finding is that factors of production are roughly evenly spread among farmers. That is, operated land size and capital are essentially unrelated to farm productivity, generating substantially larger amounts of misallocation than found in other contexts. Our main result of a near zero correlation of inputs with farm productivity is similar in both the cross-section and panel samples. Our main quantitative finding of a substantial output gain from efficient reallocation is robust to alternative factor share parameters, more flexible production technologies, and the consideration of specific crops.

We provide suggestive evidence a connection between misallocation and land markets. In particular, we show that the ratio of efficient to actual land input is reduced by $17 \%$ when farms operate rented in land. A limitation of the empirical literature on misallocation is a weak connection of misallocation with the policies and institutions that cause it (Hsieh and Klenow, 2009), a caveat that also applies to previous studies of misallocation in the agricultural sector (Adamopoulos and Restuccia, 2014). Our evidence connecting misallocation with land markets has inspired recent empirical and quantitative studies of reforms in specific contexts that corroborate the importance of misallocation in the agricultural sector such as a land-ceiling reform in the Philippines (Adamopoulos and Restuccia, 2020), a property rights reform in Pakistan (Beg, 2022), a leasing-rights reform in China (Chari et al., 2021), and a land certification reform in Ethiopia (Chen et al., 2021).

Our evidence of factor misallocation based on producer-level TFP measures is closely linked to the seminal work of Hsieh and Klenow (2009) for the manufacturing sector in China, India, and the United States. Our analysis contributes to this work by providing evidence of misallocation in the 
agricultural sector of a very poor country. Our analysis exploits the detailed micro data and the available panel dimension to address important concerns of measurement and specification errors that cast doubt on the extent of misallocation in poor countries. First, our measure of producerlevel TFP in agriculture relies on physical quantities of outputs and inputs (Beegle et al., 2012; Carletto et al., 2013) rarely available in settings outside agriculture. This allows us to evaluate our results when focusing on individual crops, addressing potential composition issues. Second, the micro data provide detailed measures on the quality of inputs such as land quality as well as transitory shocks such as rain and that we explicitly control for in our measure of farm TFP. Moreover, we use the panel dimension of the data to estimate a household-farm productivity fixed effect that removes time and transitory variation such as potential measurement error, allowing a more conservative characterization of the extent and cost of misallocation. Third, the detailed data allow us to characterize misallocation within narrow geographical areas, perform relevant robustness analysis, and to provide suggestive evidence connecting misallocation with land markets.

We also explore the consequences of misallocation for agricultural income inequality. This is relevant because the actual land allocation derives from a land institution that may be in place in part to address distributional concerns as the distribution of land can operate as an ex-ante redistribution mechanism. We show however that even though the actual allocation of factors is evenly spread across farmers, factor equalization is ineffective at equalizing incomes in Malawi since there is substantial heterogeneity in the ability of farmers to produce output with the same inputs. Treating the actual factor allocation as endowments, we show that the efficient allocation decentralized via perfectly competitive rental markets, produces a substantial reduction in agricultural income inequality - a reduction in the variance of log income from 1.7 to 1.0 -and a dramatic reduction in poverty. Essentially, agricultural income of the poorest quintile farms, which happen to be the least productive, increases by more than 18-fold due to relatively more beneficial rental income, compared to the 1.6-fold increase in income in the top quitile.

Our paper relates to a growing literature in macroeconomics using micro data to study macro 
development (Gollin et al., 2014; Buera et al., 2014; Bick et al., 2016; Santaeulàlia-Llopis and Zheng, 2018; Adamopoulos and Restuccia, 2020; Donovan, 2021). Macroeconomic studies of misallocation in the agricultural sector where initially based on the size distribution of farms across countries (Adamopoulos and Restuccia, 2014), but more recent work incorporates important features of the micro data such as Chen (2017) on the impact of land titles on agricultural productivity, Gottlieb and Grobovsek (2019) on the implications of communal land on misallocation in Ethiopia, and Adamopoulos et al. (2021) on the productivity effects of a restrictive land institution in China.

Within the micro development literature, Foster and Rosenzweig (2011) provide evidence of inefficient farm sizes in India that may be connected to the low incidence of tenancy and land sales limiting land reallocation to efficient farmers and Udry (1996) focuses on the intra household-farm reallocation of factors across wives and husbands, obtaining a relatively small role of misallocation within households in Burkina Faso. Our results instead indicate a larger role for misallocation across farms in Malawi, taking intra-household misallocation as given which is a part of our measured household-level productivity. Other studies analyze the role of tenancy and property rights for agricultural productivity (Shaban, 1987; Besley, 1995; Banerjee et al., 2002) focusing on the impact of effort and investment on farm productivity, whereas our analysis focuses on the impact of resource allocation on agricultural productivity, taking as given farm-level TFP. Integrating the role of land-market institutions on both factor misallocation and farm-level productivity is an important area for future research. Midrigan and Xu (2014) find that firms' internal capital accumulation substantially mitigates credit market imperfections after entry and a similar mitigating argument can be made regarding the role of informal credit in villages; these mitigating forces are, however, limited for land which is not reproducible, accumulates only through costly transactions, and ill-defined property rights effectively prevent even informal arrangements. This is consistent with recent empirical evidence showing that household land holdings barely grow over the life cycle in poor countries (de Magalhães and Santaeulàlia-Llopis, 2018).

The paper proceeds as follows. In the next section, we describe the data and the construction of 
the main variables for our analysis. Section 3 presents the framework for measuring farm TFP. In Section 4 we characterize the extent and cost of misallocation in agriculture and provide robustness analysis. Section 5 provides suggestive evidence connecting misallocation with land markets and discusses agricultural income inequality in an efficient allocation. We conclude in Section 6.

\section{Data}

We use a unique and detailed household-level dataset collected by the World Bank, the Malawi Integrated Survey of Agriculture (ISA). The Malawi ISA is part of a new initiative funded by the Bill \& Melinda Gates Foundation and led by the Living Standards Measurement Study (LSMS) Team in the Development Research Group (DECRG) of the World Bank. The survey is comprehensive in the collection of the entire agricultural production, such as physical amounts by crop, and the full set of inputs used in all agricultural activities, all collected by a new and enlarged agricultural module that distinguish ISA from previous LSMS surveys. The data are nationally-representative with a sampling frame based on the Census. There are four waves of the data available: 2010/11, 2013/14, 2016/17, and 2019/20 waves. We start by describing the 2010/11 wave which we use to calculate our benchmark results, followed by a description of the unbalanced panel using the other waves. See Appendix A for more details on the construction of our data.

The 2010/11 wave consists of an original sample that includes 12,271 households (and 56,397 individuals) of which $81 \%$ live in rural areas. The survey provides information on household-farm characteristics over the entire year and we focus on agricultural activities related to the rainy season which accounts for more than $90 \%$ of agricultural production in Malawi. While data for many variables is provided at the plot level, we focus our analysis on the household farm and as a result when required we aggregate plot-level information to the household farm level. Aragón et al. (2022) discuss in detail the importance of farms versus plots in assessing misallocation in small-scale 
agriculture in developing countries.

Output and value added. The data provide quantity of each crop produced in plots operated by a household. We value agricultural output using median at-the-gate prices and then aggregate the value of outputs for all plots and crops to the household-farm level. We also calculate the value of intermediate inputs, such as fertilizers, herbicides, pesticides and seeds, by applying common median prices. As a result, our benchmark measure of household-farm output is a common-price measure of real value added constructed as the value of agricultural production (of all crops) minus the costs of the full set of intermediate inputs. We use common prices of outputs and intermediate inputs to construct real value added in farms in the same spirit as using international prices to construct real measures of output across countries. This is relevant in Malawi because intermediate inputs are subsidized via the "Malawi Input Subsidy Program" and the subsidy allocation is based on farmer's income, with poorer farmers receiving higher subsidies.

Land. We measure farm land input as the sum of the size of each cultivated household plot, including rented-in land. Hence, we focus on the operational scale of the household farm. On average, household farms cultivate 1.8 plots. Importantly, plot size is recorded in acres using GPS (with precision of $1 \%$ of an acre) for $98 \%$ of plots, while for the remaining $2 \%$ of plots, size is estimated. GPS is a more precise measure of land than the more common self-reported land (Aragón et al., 2022). The average farm size is extremely small in Malawi about 0.81 hectares (henceforth, ha.), whereas comparatively average farm size is 187 ha. in the United States and 16.1 ha. in Belgium, a country with similar land per capita endowment as Malawi (Adamopoulos and Restuccia, 2014). The distribution of farm land operational scales is skewed to very small sizes: $79.9 \%$ of households operate less than 1 ha., $96.7 \%$ of households operate less than 2 ha., and only $0.2 \%$ of households operate more than 5 ha. Table 1 summarizes the size distribution of farms in Malawi from the ISA survey comparatively with Census data for Malawi, Belgium, and USA.

Land quality and rain. The data contains very detailed information on the quality of land for each 
Table 1: Size Distribution of Farms (\% of Farms by Size)

\begin{tabular}{lcccc}
\hline & $\begin{array}{c}\text { ISA 2010/11 } \\
\text { Malawi }\end{array}$ & \multicolumn{3}{c}{ World Census of Agriculture 1990} \\
Malawi & Belgium & USA \\
Hectares (Ha): & 79.9 & 77.7 & 14.6 & - \\
$\quad \leq 1 \mathrm{Ha}$ & 16.8 & 17.3 & 8.5 & - \\
$1-2 \mathrm{Ha}$ & 3.1 & 5.0 & 15.5 & 10.6 \\
$2-5 \mathrm{Ha}$ & 0.2 & 0.0 & 14.8 & 7.5 \\
$5-10 \mathrm{Ha}$ & 0.0 & 0.0 & 46.6 & 81.9 \\
$10+\mathrm{Ha}$ & 0.81 & 0.7 & 16.1 & 187.0 \\
\hline
\end{tabular}

Notes: The first column reports the land size distribution (in hectares) for household farms from Malawi ISA 2010/11. The other columns report statistics from the World Census of Agriculture 1990 for Malawi, Belgium, and United States documented in Adamopoulos and Restuccia (2014).

plot used by households. There are 11 dimensions of land quality reported: elevation, slope, erosion, soil quality, nutrient availability, nutrient retention capacity, rooting conditions, oxygen availability to roots, excess salts, topicality, and workability. We also observe weather conditions, such as the annual precipitation. This allows us to control for land quality and transitory shocks to measure household-farm productivity. Appendix A provides more detailed information and robustness on land quality and transitory shocks.

Capital. Information on farm capital is available for both equipment (implements and machinery) and structures. Capital equipment includes implements (such as hand hoe, slasher, axe, sprayer, panga knife, sickle, treadle pump, and watering can) and machinery (such as ox cart, ox plough, tractor, tractor plough, ridger, cultivator, generator, motorized pump, and grain mill), while capital structures includes chicken houses, livestock kraals, poultry kraals, storage houses, granaries, barns, pig sties, among others. To proxy for capital services after conditioning for its use in agricultural activities, we aggregate across the capital items evaluated at the estimated current selling price. The selling price for agricultural capital items, rarely available in previous LSMS data, helps capture potential differences in the quality and depreciation of capital across farms.

Labor. A large proportion of household members in Malawi contribute to agricultural work. The 
average household size is 4.6 members with extended families in which several generations live together in a single household. For family labor, the data provide information of weeks, days per week, and hours per day employed per plot, activity and individual. The data also provide information for hired labor and free labor (labor received in exchange) in labor days. We measure household-farm labor days by aggregating labor days of all plots, activities, and individuals, for all three types of labor. Note that family labor days account for the vast majority (roughly 99\%) of total labor input.

Geographic and institutional characteristics are also recorded for each household. We use partitions of these characteristics to conduct alternative analyses. In particular, we use geographical information on the region, districts, and institutional characteristics such as the traditional authority (TA) governing the household farm. TAs are relevant for our analysis as chiefs appointed by TAs perform a variety of functions that include issues related to land and property. We note that the survey response rate is high with very few missing observations.

We now explain the construction of the panel data. A subset of 2010/11 wave households was re-interviewed with the same questionnaire in 2013/14, which provides a two-period panel. The 2013/14 wave is only a re-interview wave and hence is smaller in size. In addition, there are two new cross-section waves available: 2016/17 and 2019/20. These waves are comparable to the 2010/11 wave in terms of sample size and questionnaire, but only a small number of households from the 2011/12 wave are re-interviewed in 2016/17 and 2019/20. Combining all four waves, around 2,000 farm households can be linked and appear at least twice in the panel. A non-trivial portion of households experience splitting during our sample period and we drop these households in our analysis. 


\section{Measuring Farm Productivity}

We use the micro data to measure productivity at the farm level. Constructing a measure of farm total factor productivity (TFP) is essential in assessing the extent and cost of factor misallocation in the agricultural sector. The detailed micro data for Malawi offers a unique opportunity in this assessment as data is provided in quantities of outputs and inputs. As a result, fewer assumptions are required to measure micro-level productivity compared to studies of the manufacturing sector where productivity must be inferred from plant sales or revenues.

We start by describing how we measure farm productivity using the cross-sectional data, and then explain how the panel data helps removing transitory shocks and potential measurement error. In the 2010/11 cross-sectional data, we measure farm-level total factor productivity (TFP) $s_{i}$ as the residual from the following farm-level production function,

$$
\tilde{y}_{i}=s_{i} \zeta_{i}\left(k_{i}^{\alpha}\left(q_{i} \ell_{i}\right)^{1-\alpha}\right)^{\gamma}, \quad \alpha, \gamma \in(0,1)
$$

where $\tilde{y}_{i}$ is real value added, $k_{i}$ is capital, $\ell_{i}$ is the amount of operated land, $\zeta_{i}$ is a rain shock, $q_{i}$ is land quality, and $(\alpha, \gamma)$ are input elasticities. In our analysis, we focus on the allocation of capital

and land across farms, abstracting from differences in labor inputs. For this reason, we measure value added, capital, and land in the data in per labor hour terms. This implies that our residual measure of TFP is not affected by actual differences in the labor input across farmers in the data. In constructing our measure of farm TFP, we choose $\alpha=0.67$ and $\gamma=0.54$ to match the capital and land income shares for U.S. agriculture reported in Valentinyi and Herrendorf (2008) which are 0.36 and 0.18 . We later discuss the robustness of our results to these factor shares using our micro data for Malawi.

We are interested in measuring farm productivity and hence it is important to distinguish between the productivity of the farm and the productivity of the land under operation. There are important 
differences in the land characteristics operated by farms in our sample. For the full sample, more than 32 percent of land is high-altitude plains while around 20 percent are low plateaus and 23 percent mid-altitude plateaus. These characteristics also differ by region where the Center region is mostly high-altitude plains whereas the South region is mostly low plateaus. We control for land quality in our measure of productivity by constructing a benchmark index $q_{i}$ regressing log output in each farm on the full set of land quality dimensions available in the data. To the extent that farm inputs are positively related to land quality, our benchmark index potentially attributes too much variation to land quality. We nevertheless use this index as our benchmark because it is conservative with respect to the productivity effects of misallocation. We consider alternative land quality indexes with similar results, see Appendix A.

There is substantial variation in land quality $q_{i}$ across households and across regions, but this variation does not account for much of the variation in output compared to variation in farm TFP. In Malawi 2010/11 cross-section, the dispersion (variance of the log) of land quality indexes is 0.60 , the dispersion in the quantity of land across households is 0.66 , while that of output is 1.80. Not surprisingly, the dispersion in land quality decreases substantially when restricting by geographical area, the average dispersion is 0.59 within regions, 0.42 within districts, and 0.08 within enumeration areas. Reassuringly, our calculated land quality index is positively correlated with self-reported estimated land price (Appendix A).

We also control for rain shocks, which is the single most important source of transitory shocks to agricultural production in Malawi since a vast majority (99\%) of agricultural land plots are rain-fed without alternative irrigation systems. We measure rainfall shocks using information on annual precipitation. To exclude rainfall shocks in estimating farm productivity, we regress farm value added on dummy variables indicating deciles of precipitation and then explicitly controlling for this effect from precipitation $\zeta_{i}$ in equation (1). Note that rain is not a substantial contributor to output variation across farm households. In Malawi 2010/11 cross-section, the variance of logs of rain index $\zeta_{i}$ is 0.03 for our entire sample, which is small compared to the dispersion in land size and output. 
The small role of rain variation further appears within regions, districts, and enumeration areas, as well as using alternative definitions of precipitation measures such as the precipitation of the wettest quarter.

Table 2 reports the variance decomposition of farm value added per hour using our assumed production function. We note that farm productivity $s_{i}$ and to a lesser extent the inputs of capital and land are the key determinants of output variation across farm households in Malawi, with rain and land quality playing a quantitatively minor role. Specifically, the variance of farm TFP accounts for 78 percent of the total variance of output and the variance of capital and quality adjusted land inputs for about 17 percent.

Table 2: Variance Decomposition of Agricultural Output

\begin{tabular}{lrr}
\hline & Level & $\%$ \\
Output, $\operatorname{var}(\tilde{y})$ & 1.804 & 100.0 \\
Productivity, $\operatorname{var}(s)$, & 1.402 & 77.7 \\
Rain, $\operatorname{var}(\zeta)$ & 0.033 & 1.8 \\
Inputs, $\operatorname{var}(f(k, q \ell))$ & 0.307 & 17.0 \\
$2 \operatorname{cov}(s, \zeta)$ & -0.014 & -0.8 \\
$2 \operatorname{cov}(s, f(k, q \ell))$ & 0.070 & 3.9 \\
$2 \operatorname{cov}(\zeta, f(k, q \ell))$ & 0.007 & 0.4 \\
\hline
\end{tabular}

Notes: The variance decomposition uses our benchmark production function in equation (1) written as $\tilde{y}_{i}=$ $s_{i} \zeta_{i} f\left(k_{i}, q_{i} \ell_{i}\right)$. All variables have been logged. The variables are value added $\tilde{y}_{i}$, household-farm productivity $s_{i}$, rain $\zeta_{i}$, structures and equipment capital $k_{i}$, and quality-adjusted land size, $q_{i} \ell_{i}$. The first two columns report results from our benchmark specification where rain and land quality are controlled for. The column "Level" reports the variance and the column "\%" reports the variance contribution to the total in percentage. Data for Malawi ISA $2010 / 11$.

With the estimated farm productivity $s_{i}$, we then calculate (net) output $y_{i}$ that does not include transitory rain shocks $\zeta_{i}$ and land quality $q_{i}$ as

$$
y_{i}=s_{i}\left(k_{i}^{\alpha} \ell_{i}^{1-\alpha}\right)^{\gamma}
$$

We use this calculated (net) output $y_{i}$ in assessing the productivity gain associated with resource reallocation in Section 4. 
Having constructed our measure of farm TFP $s_{i}$, we compare the magnitude of productivity dispersion to that of physical productivity (TFPQ) across plants in the manufacturing sector in the United States, China, and India reported in Hsieh and Klenow (2009) in Table 3. Whereas the ratio of physical productivity between the 90 to 10 percentile is a factor of around 15-fold in China and India and around 9-fold in U.S. manufacturing, the 90-10 ratio across farms in our sample is 18-fold. Similarly, the 75-25 ratio is 4 -fold in our sample of farms whereas it is around 4.5-fold across manufacturing plants in China and India.

Table 3: Productivity Dispersion across Farms and Manufacturing Plants

\begin{tabular}{lcccccc}
\hline & \multicolumn{3}{c}{ Agricultural Farms } & \multicolumn{3}{c}{ Manufacturing Plants } \\
& \multicolumn{2}{c}{ Malawi ISA } & USA & USA & China & India \\
Statistics & $2010 / 11$ & Panel & 1990 & 1977 & 1998 & 1987 \\
\hline Standard deviation of log & 1.18 & 0.93 & 0.80 & 0.85 & 1.06 & 1.16 \\
75-25 log difference & 1.39 & 1.22 & 1.97 & 1.22 & 1.41 & 1.55 \\
90-10 log difference & 2.89 & 2.35 & 2.50 & 2.22 & 2.72 & 2.77 \\
Number of observations & 7,505 & 608 & - & 164,971 & 95,980 & 31,602 \\
\hline
\end{tabular}

Notes: Statistics for the household-farm productivity distribution reported from Malawi ISA 2010/11 in the first column and the panel sample in the second column. The third column reports statistics for farm productivity in the United Sates from the calibrated distribution in Adamopoulos and Restuccia (2014) to U.S. farm-size data. The other columns report statistics for manufacturing plants in Hsieh and Klenow (2009). SD is the standard deviation of $\log$ productivity; $75-25$ is the $\log$ difference between the 75 and 25 percentile and $90-10$ the 90 to 10 percentile difference in productivity. $\mathrm{N}$ is the number of observations in each dataset.

To further minimize the impact of transitory shocks and potential measurement error, we exploit the available waves to construct a panel data of farms described in Section 2. We restrict the panel sample to those households who appear in the 2010/11 wave (the benchmark year for quantitative analysis) and at least one of the 2013/14, 2016/17, and 2019/20 waves. Our approach to estimate farm productivity using the panel data follows Chen et al. (2021) and Adamopoulos et al. (2021). In essence, we separately estimate farm productivity $s_{i t}$ as in the cross-section for all four waves of the data and then use these values to estimate a household-farm fixed effect which we denote by $\bar{s}_{i}$. This household-farm productivity fixed effect is devoid of time and other transitory variations.

Table 3 , second column, reports statistics on $\bar{s}_{i}$ estimated using our panel data with this approach. 
The dispersion of farm productivity is substantially lower than our cross-sectional results, and it is also lower than that of the U.S. agriculture or that of China and India's manufacturing plants. We hence conclude that the panel data provides a more conservative estimate of farm productivity and we also use it to assess the productivity cost of misallocation in the next section.

\section{Quantitative Analysis}

We assess the extent of factor misallocation across farms in Malawi and its quantitative impact on agricultural productivity. We do so without imposing any additional structure other than the farm-level production function assumed in the construction of our measure of household-farm productivity. We then evaluate the robustness of our main results with respect to values of factor shares, different elasticity of substitution between capital and land in production, crop composition, and potential measurement error.

\subsection{Efficient and Actual Allocations}

As a benchmark reference, we characterize the efficient allocation of capital and land across a fixed set of heterogeneous farmers that differ in productivity $s_{i}$. A planner chooses the allocation of capital and land across a given set of farmers with productivity $s_{i}$ to maximize agricultural output given fixed total amounts of capital $K$ and land $L$. The planner solves the following problem:

$$
Y^{e}=\max _{\left\{k_{i}, \ell_{i}\right\}} \sum_{i} s_{i}\left(k_{i}^{\alpha} \ell_{i}^{1-\alpha}\right)^{\gamma}
$$

subject to

$$
K=\sum_{i} k_{i}, \quad L=\sum_{i} \ell_{i}
$$


The efficient allocation equates marginal products of capital and land across farms and has a simple

form. Letting $z_{i} \equiv s_{i}^{1 /(1-\gamma)}$, the efficient allocations are given by simple shares of a measure of productivity $\left(z_{i} / \sum z_{i}\right)$ of capital and land:

$$
k_{i}^{e}=\frac{z_{i}}{\sum z_{i}} K, \quad \ell_{i}^{e}=\frac{z_{i}}{\sum z_{i}} L
$$

We note for further reference that substituting the efficient allocation of capital an land into the definition of aggregate agricultural output renders a simple constant returns to scale aggregate production function for agriculture on capital, land, and agricultural farms given by

$$
Y^{e}=A N_{a}^{1-\gamma}\left(K^{\alpha} L^{1-\alpha}\right)^{\gamma}
$$

where $A=\bar{z}^{1-\gamma}$ is measured total factor productivity, $N_{a}$ is the number of farms, and $\bar{z}=\sum_{i} z_{i} / N_{a}$ is average productivity of farmers. For our benchmark, we choose $\alpha$ and $\gamma$ consistent with the production function used in constructing our measure of farm-level productivity, $\alpha=0.67$ and $\gamma=0.54$, values chosen to match the capital and land income shares in U.S. agriculture. The total amount of capital $K$ and land $L$ are the total amounts of capital and land across the farmers in the data. Farm level productivity $s_{i}$ 's are given by our measure of farm TFP from data as described previously.

We illustrate the extent of factor misallocation in Figure 1, where we contrast the actual allocation of land and capital and the associated factor productivities by farm TFP with the efficient allocation of factors and factor productivities across farms. Each (blue) dot represents a household farm in the data whereas the (red) dashed line represents the efficient allocation. The (blue) solid line is the best fit of the data. In the efficient allocation, operational scales of land and capital are increasing in farm productivity so that factor productivities are constant across farms. The patterns that emerge in comparing the efficient allocation with actual allocations are striking as the efficient allocation contrasts sharply with the actual allocation of capital and land in Malawi. The data show that 
operational scales of land and capital in farms are unrelated to farm productivity.

Figure 1, panel (a), shows the amount of land operated by each farm against farm productivity using our baseline measure of productivity that adjusts for rain and quality as described previously. Contrary to the efficient allocation where there is a tight mapping between land size and TFP, actual land in farms is essentially uncorrelated to farm TFP, the correlation between land size and productivity is 0.17 . This pattern implies that the average (or marginal) product of land is not equalized across farms as it would be the case in the efficient allocation. Figure 1, panel (b) documents the marginal product of land (which in our framework is proportional to the output per unit of land or yield) across farms, which is strongly positively related to farm TFP with a correlation (in logs) of 0.89 .

Figure 1, panel (c), documents the relationship between the amount of capital in farms by farm productivity. As with land, capital and productivity across farms are essentially unrelated, the correlation between the two variables is 0.02. And this pattern implies an increasing marginal product of capital with farm TFP which we document in panel (d) with a correlation between these variables (in logs) of 0.89 . Although not documented in the figure, the data indicates that the capital to land ratio is essentially unrelated to farm productivity, with a slight negative correlation between these variables $(-0.13)$. This finding suggests that larger farms use more capital but since larger farms are not more productive on average, the capital to land ratio remains roughly constant with respect to farm TFP. Figure 1 reports variables using the Malawi ISA 2010/11 cross-sectional wave, however, the patterns remain remarkably similar if we use instead the panel data. For instance, the $\log$ correlation between land size and productivity is 0.21 in the panel sample compared to 0.17 in the 2010/11 cross-section (see Appendix B.1.)

Regarding land, we emphasize that the land market is largely underdeveloped in Malawi. The proportion of household-farms that do not operate any marketed land is $84.5 \%$. These are households whose land was granted by a village chief, was inherited or was given as bride price. The remaining 
Figure 1: Land Size, Capital, MPL and MPK: Actual and Efficient Allocations

(a) Land Size vs. Farm Productivity

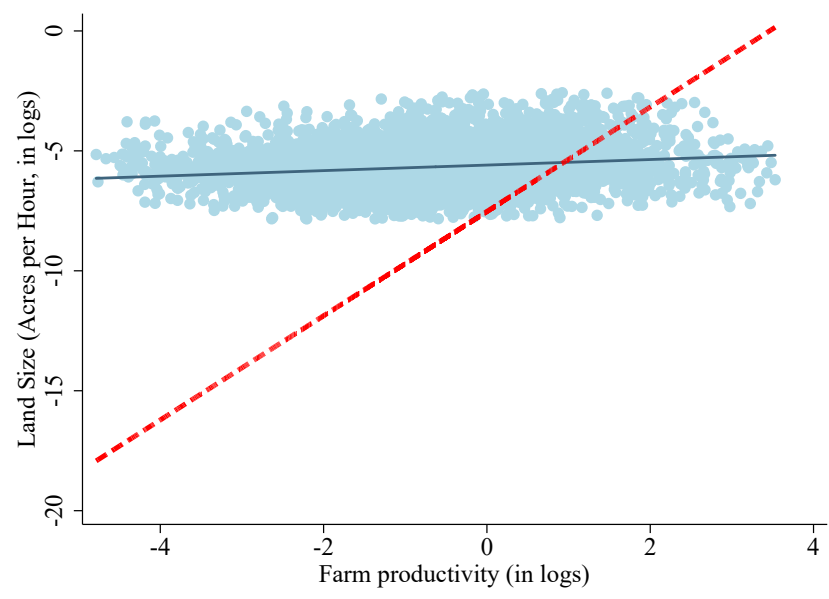

(c) Capital vs. Farm Productivity

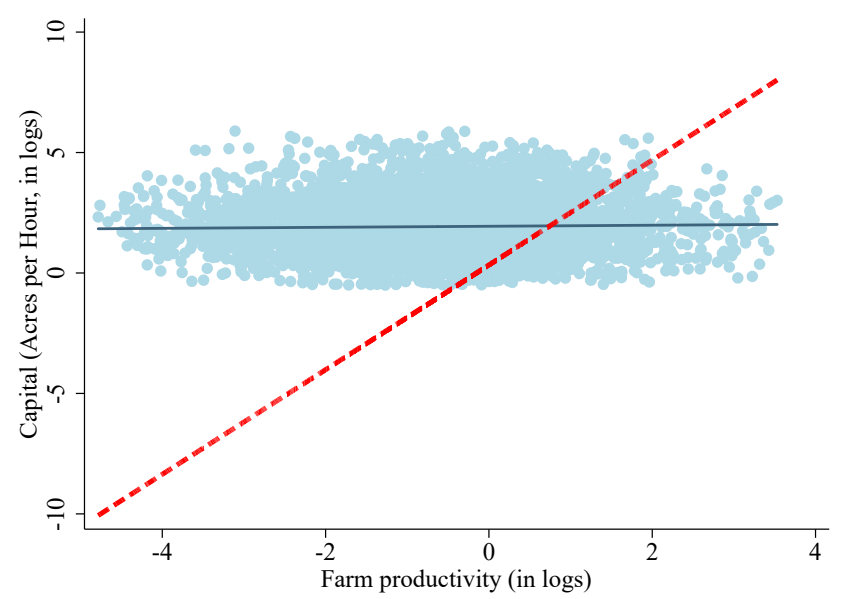

(b) MPL vs. Farm Productivity

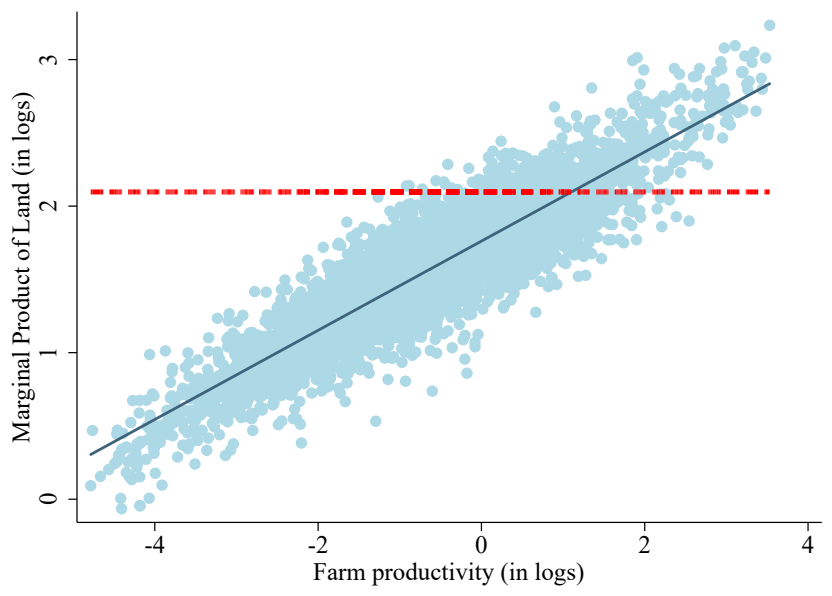

(d) MPK vs. Farm Productivity

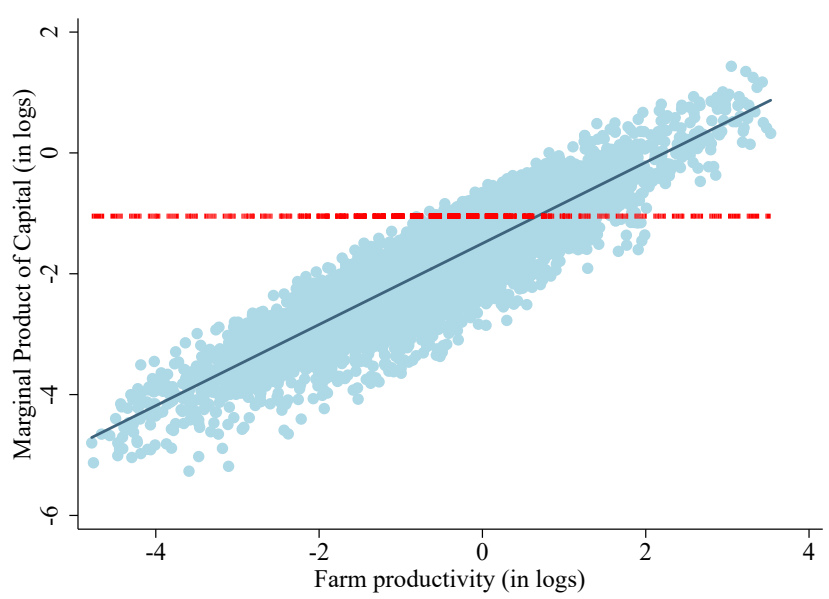

Notes: Panel (a) reports actual and efficient land operational size in farms $l_{i}$ with respect to farm productivity $s_{i}$. Panel (b) reports actual and efficient marginal product of land (MPL) with respect to farm productivity $s_{i}$. Panel (c) reports actual and efficient capital in farms $k_{i}$ with respect to farm productivity $s_{i}$. Panel (d) reports actual and efficient marginal product of capital (MPK) with respect to farm productivity $s_{i}$. Each (blue) dot represents a household farm in the data whereas the (red) dashed line represents the efficient allocation. All variables have been logged. Data are for the 2010/11 cross-sectional wave. 
15.5\% of farm households operate some land obtained from the market, either rented or purchased, and the proportion of household-farms whose entire operated land was obtained in the market is 9.8\%. In this context, our finding that the actual allocation of land across farmers in Malawi is unrelated to farm productivity is consistent with the institutional setting where the amount of land in farms is more closely related to inheritance norms and redistribution, and access to land is severely restricted in rental and sale markets so more productive farmers cannot grow their size.

Capital is also unrelated to farm productivity with the capital to land ratio being roughly constant across farm productivity. Our interpretation of this fact is that restrictions to land markets are also affecting capital allocations echoing de Soto (2000)'s findings that land market restrictions and insecure property rights of farmers limit the ability to raise capital for agricultural production (Besley and Ghatak, 2010).

To relate our findings with the broader literature on misallocation, we compute a summary measure of distortions which are implicit in the nature of land distribution and frictional reallocation. As in Hsieh and Klenow (2009), we compute farm revenue productivity (TFPR) as the ratio of output to composite input, that is

$$
\mathrm{TFPR}_{i}=\frac{y_{i}}{k_{i}^{\alpha} \ell_{i}^{1-\alpha}}
$$

This is a summary measure of distortions since it equalizes across farms in an efficient allocation. The dispersion in this measure of distortions is quite high in Malawi, a standard deviation of log of 1.22. In addition, distortions are quite correlated with farm productivity, a correlation of log farm TFPR and log farm TFP of 0.94. Using instead the panel sample, the dispersion in distortions falls to 0.99 but the correlation between distortions and farm productivity remains quite high 0.90.

Our findings constitute strong evidence of land and capital misallocation across farmers in Malawi. 


\subsection{Aggregate Output Gain}

To assess the impact of misallocation on agricultural productivity, in what follows we report the aggregate output gain defined as the ratio of efficient to actual aggregate output,

$$
\frac{Y^{e}}{Y}=\frac{Y^{e}}{\sum y_{i}},
$$

where $Y^{e}$ is efficient aggregate agricultural output defined previously and $Y$ is actual agricultural output aggregated from farm-level output $y_{i}$ using the production function in equation (1) with our measure of farm productivity and the actual amounts of capital and land operated by each farm. This is a standard measure of the cost of misallocation in the literature (Hsieh and Klenow, 2009). Recall that the computation of actual output at the farm level abstracts from rain and land quality and hence is comparable to the efficient output described previously since our measure of farm productivity $s_{i}$ is purged of rain and land quality effects. Because the efficient output takes as given the total amounts of capital, land, and the number of farmers observed in the data, the output gain is also an agricultural TFP gain. Note that Hopenhayn (2014) proposes a measure of misallocation which summarizes on average how much factors are distorted relative to the efficient benchmark weighted by farm productivity: $\sum\left(k_{i} / k_{i}^{e}\right)^{\alpha \gamma}\left(\ell_{i} / \ell_{i}^{e}\right)^{(1-\alpha) \gamma} z_{i} / \sum z_{i}$. This measure is exactly the inverse of our calculated output gain.

Table 4, panel (a), reports the main results. For the full cross-sectional sample in Malawi, the output gain is 2.82-fold, that is, if capital and land were reallocated to their efficient use, aggregate output and hence productivity would increase by 182 percent. This is a very large increase in productivity as a result of a reduction in misallocation compared to results when evaluating specific policies which have found increases on the order of 5 to 30 percent (Restuccia and Rogerson, 2017), and somewhat larger than the gains when eliminating plant-level wedges in manufacturing in China and India ranging between 100 to 160 percent (Hsieh and Klenow, 2009). Given that the productivity dispersion across farms in Malawi is similar to that of manufacturing plants in 
China and India, a larger reallocation gain suggests that resources across farms in Malawi are more misallocated than across pants in those other countries. Not only is the standard deviation of log revenue productivity in Malawi 1.22 higher than those in the case of India and China 0.67-0.74, but also inputs are essentially no correlated with farm TFP in Malawi whereas the input correlation is higher in those other countries. Because we have a large sample, our mean output gain is tightly estimated with a standard error of 0.19 obtained from bootstrap estimates.

Table 4: Agricultural Output Gain $\left(Y^{e} / Y^{a}\right)$

\begin{tabular}{lccc}
\hline & Cross-section & \multicolumn{2}{c}{ Panel data } \\
& $2010 / 11$ & FE $s_{i}$ & + FE inputs \\
\hline (a) Nationwide reallocation & 2.82 & 1.96 & 1.67 \\
& $(0.19)$ & $(0.22)$ & $(0.14)$ \\
(b) Local reallocations & & & \\
Regions & 2.78 & 1.80 & 1.60 \\
& $(0.19)$ & $(0.14)$ & $(0.11)$ \\
Districts & 2.68 & 1.57 & 1.48 \\
& $(0.15)$ & $(0.08)$ & $(0.06)$ \\
Traditional authority & 2.32 & - & - \\
Enumeration areas & $(0.09)$ & & - \\
(c) Across productivity- $s_{i}$ variation & 1.84 & - & 1.52 \\
& $(0.05)$ & & $(0.13)$ \\
& 2.38 & 1.51 & 608 \\
\hline
\end{tabular}

Notes: Aggregate output gain as the ratio of efficient to actual output in various setups. Panel (a) reports nationwide reallocation. Panel (b) reports reallocations within narrower definitions of geographical areas. We drop areas with fewer than 5 household-farm observations. Panel (c) reports output gains associated with across productivity- $s_{i}$ variation. The first column are results for the 2010/11 cross-section, and the second and third columns are results using the panel data, where we estimate household-farm productivity fixed effects and household farm productivity and inputs fixed effects. We omit reallocation results within traditional authority and enumeration areas due to sample size. Confidence intervals in brackets are obtained from bootstrap with 1,000 repetitions drawn with replacement clustered at the enumeration area level.

We also calculate the output gain from reallocation within narrower definitions of geographical areas. Specifically, we calculate the output gain of an efficient reallocation of resources within each geographical area, and report the weighted average of output gains among all areas, using the actual aggregate output in each area as weight. In addition, narrower geographic definitions 
provide additional land quality controls, see Larson et al. (2014) for a similar strategy. The results are reported in Table 4. The output gain is lower when restricting factor reallocation within narrower geographical areas, but even with the narrowest geographical definition (enumeration areas), the output gain is still substantial 1.84-fold, i.e., reallocating resources within each enumeration area comprising about 16 households and about 30 acres of geographically connected land, increases agricultural output by 84 percent. We find similar results using median geographical areas.

Factor inputs are severely misallocated in Malawi, implying the large aggregate productivity gains just discussed. There are two features of factor misallocation in Figure 1, panels (a) and (c): factor inputs are dispersed among farmers with similar productivity (misallocation in factor inputs within $s_{i}$ productivity types) and factor inputs are misallocated across farmers with different productivity (which lowers the correlation of factor inputs with farm productivity). We argue that factor input variation within a farm-productivity type is not likely due to measurement error as factor inputs in farms such as land are measured with relative precision via GPS. Nevertheless, we can assess the magnitude of the aggregate output gain associated with no dispersion in factor inputs within a productivity type as if this variation was all due to errors. We remove within- $s$ variation in factor inputs by regressing separately log land and capital on a constant and log farm productivity $s$ and use the estimated relationship to construct measures of factor inputs that remove the residual variation. The results for the across $s_{i}$ misallocation are reported at the bottom of Table 4 . Reallocating resources across different productivity farms $s_{i}$ implies an output gain that is still substantial 2.38fold (compared with 2.82-fold across all farms). This implies that 84 percent $(\log (2.38) / \log (2.82))$ of the overall output gain is due to misallocation across farmers with different productivity, with 16 percent due to variation across farms with the same productivity.

We further calculate the output gain using our panel data. Recall that we have four waves of data: 2010/11, 2013/14, 2016/17, and 2019/20. We separately estimate household-farm productivity for each of the four waves and then estimate a household-farm fixed effect, which is devoid of time and other transitory variations including potential measurement error. We then use these fixed- 
effect estimates of farm productivity together with capital and land input information from the 2010/11 wave to assess the output gain from reallocation. The results are reported in the second column of Table 4. The output gain associated with nationwide reallocation is 1.96 -fold, which is lower than the cross-sectional estimate but still quite substantial. Since the fixed-effect estimates of productivity abstract from transitory variation the lower output gain of reallocation is potentially a conservative estimate of the cost of misallocation.

We also use the panel data to estimate household-farm fixed effects for inputs, in addition to farm productivity. This specification further reduces variation in inputs which may be real or due to potential measurement error. The results are reported in the third column of Table 4. The output gain from nationwide reallocation is 1.67 -fold in this case. Comparatively, this reallocation gain is similar in magnitude to the nationwide reallocation in China (53 percent) that features a land institution similar to that in Malawi (Adamopoulos et al., 2021). We note that this specification could potentially under-estimate output gain since we abstract from overtime variations in productivity and input - for instance, land expropriation and land adjustment can be frequent in the developing world while these are averaged out in this specification. Nevertheless, even in this case the output gain remains quite substantial, corroborating the importance of misallocation in agriculture in Malawi.

\subsection{Robustness}

Factor Shares. We restrict agricultural factor shares to those in the United States in our baseline measure of farm productivity to limit the impact of factor-market distortions in Malawi on our estimates. However, the production technology of the U.S. agricultural sector might differ from that in Malawi due to their different stage of development (Chen, 2020). To address this issue, we use household-farm rented-in land and capital payments reported in our micro data to compute, respectively, the land and capital share of income for the agricultural sector in Malawi and then 
use these factor shares to redo our measures of productivity and reallocation gains. Specifically, we measure factor shares of output using the average rental rates of land and capital. We compute these rates as the ratio of factor rental payments to the factor stocks from the sample of farms that rent-in capital and land. Then we use these rental rates to impute the land and capital rental income for all farms in the entire sample. This implies an average capital share of income of 0.18 and an average land share of income of 0.37 . With these factor shares, the output gain in the full sample is 2.78-fold, close to the 2.82-fold in our baseline calibration. We hence conclude that our results do not depend crucially on factor shares using Malawi data.

Rather than factor shares of capital and land, the results are more sensitive to the implied income share of labor. This is because in our framework, the share of labor is determined by the extent of decreasing returns in the farm production function $\gamma$. In the misallocation literature, there is not a lot of guidance as to the exact value of this parameter. A large quantitative literature considers values between 0.8-0.85 (e.g. Restuccia and Rogerson, 2008), whereas monopolistic competition frameworks such as that in Hsieh and Klenow (2009) and Yang (2021) consider a preference curvature parameter that maps into decreasing returns from 0.5 to 0.67 (for an exposition of this mapping see Hopenhayn, 2014). The value of $\gamma$ is 0.54 in our baseline calibration to U.S. shares (and 0.55 using using factor shares from Malawi data above). Hence, our calibration estimates are relatively low compared to the values typically considered in the literature. For each value of $\gamma$, we recompute farm productivity and the output gains from reallocation. While the output gains become small for small values of $\gamma$, in the range of plausible values, i.e., 0.4, 0.5, 0.6, 0.7, and 0.8, the output gains are 1.85, 2.45, 3.52, 5.60, and 9.86-fold, respectively. That is, using values of $\gamma$ closer to those considered in other studies outside agriculture would substantially increase the output gains from reallocation.

Technology. We also explore a constant elasticity of substitution (CES) production technology instead of the Cobb-Douglas specification and find that our results remain fairly robust to different 
values for the elasticity of substitution between capital and land. Specifically, we consider the following technology:

$$
y_{i}=s_{i}\left(\alpha k_{i}^{\frac{\varepsilon-1}{\varepsilon}}+(1-\alpha) \ell_{i}^{\frac{\varepsilon-1}{\varepsilon}}\right)^{\gamma \frac{\varepsilon}{\varepsilon-1}}
$$

where $\gamma=0.54$ and $\alpha=0.67$ to match the baseline parameter values. In this specification $\varepsilon$ is the elasticity of substitution between capital and land. An elasticity of substitution of $\varepsilon=$ 1 matches our baseline Cobb-Douglas production function. We experiment with two values of the elasticity of substitution: more substitutability than Cobb-Douglas which we set to $\varepsilon=1.32$ following Binswanger (1974) and Adamopoulos and Restuccia (2014), and less substitutability which we set to $\varepsilon=0.10$ (note perfect complementarity is $\varepsilon=0$ ). The output gain associated with nationwide reallocation is 3.06-fold and 2.74-fold in these two alternative specifications, quite similar to the output gain of 2.82 -fold in our baseline specification.

Another concern regarding the agricultural technology is the potential limit of capital and land that a farmer can operate. This is closely related to the choice of the span-of-control parameter $\gamma$ that governs the relationship between the optimal operational scale and farm productivity. In our baseline experiment, the efficient allocation implies that the largest farm operates around 321 hectares. To provide context on the magnitude of this operational scale, we note that in 2007 U.S. Census of Agriculture, the average farm size is 169 hectares and around 8 percent of farms operate more than 400 hectares. As a result, a farm size of 321 hectares is well within a technological possibility. Nevertheless, we assess the sensitivity of the efficient reallocation gains to the extent of large operational scales.

We consider a "technological" farm-size ceiling in the efficient allocation, that is we consider a maximum amount of capital and land that a farmer can operate so that the ceiling does not affect the capital-to-land ratio. We consider three types of ceilings: (1) no farm can operate more than 12 hectares, which is the largest farm size observed in our cross-sectional 2010/11 sample in Malawi, (2) no farm can operate more than 5 times their current land input, and (3) no farm can operate 
more than 2 times their current land input. Note that these "technological" limits are substantially more restricted than observed farm sizes in the U.S. data, and hence are conservative in terms of technology capacity. We find output gains are 2.37, 1.84, and 1.49-fold in each of these scenarios. We conclude that even with restrictive farm-size capacity, the gains from an efficient allocation of resources are still substantial.

Misallocation within crops. In our data, most of the agricultural land, around 80 percent, is devoted to maize production. Maize, cassava, and potatoes are the main crops produced in Malawi in terms of volume with roughly equal amount in tonnes, but it is maize that occupies the vast majority of cropland. The importance of maize further appears in terms of the household diet in Malawi where about $65 \%$ the average daily calorie intake in rural areas is obtained from maize (de Magalhães et al., 2019). Since the technology and optimal farm operational scale may differ across crops, we assess whether the magnitude of output gain differs across farms producing maize or other crops.

We consider reallocation among farmers who produce only maize, which represents about 25 percent of farmers in our data. An efficient reallocation of resources among maize farmers implies an output gain of 2.78-fold, very similar to the 2.82-fold gain in the baseline. We also consider reallocation among farmers that produce a positive amount of maize or that maize production share is above the median of all farms. The output gains in these cases are 2.85 and 2.72-fold, again similar to our baseline specification. Reallocation among farmers who mainly produce non-maize, that is farmers whose maize production share is below the median of all farms, implies an output gain of 2.61-fold. We hence conclude that crop composition and the dependence of maize production in Malawi are not critical in determining the the extent and cost of factor misallocation in Malawi agriculture.

Measurement error. There are relevant concerns regarding the potential for measurement error in survey data, especially in small-scale agriculture (e.g. Deininger et al., 2012; de Nicola and 
Giné, 2014). For instance, existing studies document potential measurement problems associated with yields (Lobell et al., 2020), labor input (Arthi et al., 2018), fertilizer quality (Bold et al., 2015), self-reported output and land (Desiere and Jolliffe, 2018), together with specific concerns on underreporting and recall bias (de Magalhães and Santaeulàlia-Llopis, 2018). Despite good quality data, our data are not free of these concerns. More specifically, measurement error may manifest itself as dispersion in estimated farm TFP and hence the calculated output gain may be affected by measurement error. Our analysis attempts to address these concerns of measurement error by estimating household-farm fixed effects using the panel data that control for transitory variation and potential measurement error. We indeed find smaller output gains in the panel specifications even though they are still sizeable. In addition, our unit of analysis is the household farm whereas many studies emphasize measurement error at the plot level (see Aragón et al., 2022, for a discussion of the plot versus the farm in assessing misallocation in agriculture). The evidence suggests that farmlevel observations may feature less measurement error than plot-level observations. Nevertheless, in this section, we explore to what extent our results may still be affected by measurement error. We conduct several counterfactual experiments to assess the potential role of measurement error and summarize our findings. Appendix B contains a more detailed description of this analysis.

To start, we assess the role of recall bias in the data by focusing on those farmers whose survey date is within four months of the time they finish harvest. Recall bias should be smaller among these farmers. We find that, however, the calculated output gain is 2.78-fold among these farmers, very similar to our baseline result of 2.82. This finding suggests that our results are unlikely to be driven by recall bias. In addition, our measure of capital relies on household's estimate of the resale value. To investigate how sensitive our results are to this measure, we consider an extreme case by setting the elasticity of capital in the production function to zero. We find an output gain of 2.96 in this case, again similar to our baseline result of 2.82 .

We also assign actual inputs $\left(k_{i}, \ell_{i}\right)$ to different farmers that differ in their farm TFP $\left\{s_{i}\right\}$ following perfectly positive and negative assortative assignments. Note that in each case, the distribution 
of inputs is as in the data, but the different assignments create different amounts of misallocation. The implied output gain associated with resource reallocation ranges from 1.35 -fold in the case of perfectly positive assortative matching between inputs and productivity to 5.38 -fold in the case of perfectly negative assortative matching. Our baseline output gain of 2.82-fold lies in between, largely because of the low correlation between farm inputs and productivity observed in the data.

We also explore a structural model to allow for a more explicit role of measurement error. We ask, given our most conservative output gain of 1.67-fold associated with fixed effect estimates of inputs, outputs, and productivity. If we believe that this output gain is still largely driven by measurement errors, and the inputs and outputs are all observed with additive measurement errors, how large should measurement errors be if the true output gain is instead, say, half of this level? In other words, this experiment informs us of the elasticity between the magnitude of measurement errors and the calculated output gain. It turns out that measurement error needs to be very large such that the true output gain is half of the calculated number. Specifically, the model implies the variance of (log) observed land input (with measurement error) to be almost twice of that of true land input (without measurement error). We think this is unlikely since farm land input is measured via GPS.

We conclude that it is unlikely that measurement error is driving our main result of a substantial output gain associated with a more efficient allocation of resources in Malawi agriculture, a conclusion that is in line with recent studies of the agricultural sector applying panel methods to assess measurement error (Adamopoulos et al., 2021; Aragón et al., 2022).

\section{Discussion}

We discuss our results by relating misallocation to the extent of land markets in Malawi and developing the implications of misallocation for agricultural income inequality. 


\subsection{The Role of Land Markets}

We find strong evidence of capital and land misallocation in the agricultural sector in Malawi. We now provide suggestive evidence connecting factor misallocation with limited market for land in Malawi. We use plot-level information about how each plot of land was acquired by the household and group household-farms by the share of land operated that is marketed, that is land that is rented in. In the 2010/11 wave of data, we find that 84.5 percent of all household farms operate only non-marketed land and the remaining 15.5 percent operate some marketed land, with 9.8 percent operating exclusively marketed land. Marketed land represent about 22 percent of cultivated land in Malawi. Note that our classification of marketed land is generous in terms of the potential for the market to direct resources to best use since many land exchanges are between family and relatives, more than half of rented in land involve zero rental price, and the size of rented land is relatively small given that farmers only have user rights of land to meaningfully separate land use from land rights.

Nevertheless, we use the efficient allocation calculated in Section 4 to separately calculate the output gain for farmers with marketed land and without. The output gain is 2.95-fold for farmers without marketed land, slightly higher than our baseline gain of 2.82-fold, while the output gain is 2.37-fold

for farmers with some marketed land. The output gain for farmers that only operate marketed land is even lower, 1.96-fold. Note that the difference in output gain across groups may reflect differences in misallocation or in the farm TFP distribution. We hence consider an alternative characterization of the role of land rentals on misallocation. We construct a measure of farm misallocation as the ratio of efficient to operated land input and regress this ratio (in log) on a dummy variable indicating the use of marketed (rent-in) land controlling for farm TFP. We find that farm misallocation, as the ratio of efficient to operated land, decreases significantly by 17 percent with marketed land.

Even though we find a reduction in the extent of misallocation among farms operating marketed land, these farms are still quite far from operating at their efficient scale, that is there remains 
substantial gains to reallocation even for farms that only operate marketed land. For instance, the correlation between land size and farm TFP is 0.15 for farms with no marketed land, 0.22 for farms with some marketed land, and 0.26 for farms that operate only marketed land, while the efficient allocation requires a correlation of one. This is consistent with evidence in other African countries with similar restrictive land institutions where the extent of rental markets remain low and not fully effective in allocating resources to best use (Chen et al., 2021).

In this regard, there is recent causal evidence on the importance of land institutions and rental markets for misallocation in the agricultural sector, for instance, a property-rights reform associated with digitization of land titles in Pakistan (Beg, 2022), a rural land contracting law in China that formalizes leasing rights (Chari et al., 2021), and a land certification reform in Ethiopia (Chen et al., 2021). In all these studies, the reform induces more land rental activity that improves resource allocation and productivity in the agricultural sector.

\subsection{Income Inequality Implications}

Unlike the actual distribution of factors in the Malawian economy which is fairly uniform across farmers with different productivity, the efficient allocation implies a substantial increase in the dispersion of operational scales, in terms of the distribution of operated capital and land across farmers. This important redistribution of factors across farmers may lead to concerns over the distributional implications of reform, especially if the actual allocation of factors reflect policy and institutional choices motivated to alleviate poverty and distributional considerations.

We assess the distributional implications of efficient operational scales. Table 5 reports the actual and efficient distribution of factors, output, and income across farmers by productivity. Whereas the actual distribution of land across farm TFP is fairly uniform, the efficient distribution implies that the top quintile of farm TFP operates almost 5 times of the average size, representing 97 percent of the total land. This implies a substantial redistribution of factors to achieve higher 
levels of agricultural productivity. We note that despite relative equalization of factor inputs across farmers, the actual distribution of income is widely dispersed in Malawi, in fact as dispersed as the distribution of productivity. For instance, taking agricultural output as a measure of farm income, the ratio of top to bottom quintile of income is a factor of 35-fold even though the ratio of capital and land inputs is within a factor of 1 to 2-fold. This suggests equalizing inputs across farm households is not effective in equalizing incomes. This insight should not be entirely surprising since our analysis indicates substantial heterogeneity in the productivity of farms to generate income with similar amounts of inputs.

To gauge the distributional effects on agricultural income of efficient factor reallocation we pursue the following counterfactual. We consider the actual distribution of factors as endowments and allow the efficient allocation to be achieved via perfectly competitive rental markets. Given competitive rental rates of capital and land that clear the capital and land markets, we compute the income associated with the efficient allocation which is given by the farm's operating income plus factor rental income as:

$$
\text { counterfactual income }=y^{e}+r_{k}\left(k^{a}-k^{e}\right)+r_{l}\left(\ell^{a}-\ell^{e}\right)
$$

where $y^{e}$ is efficient output, $\left(k^{a}, \ell^{a}\right)$ are the actual allocations of capital and land which we take as endowments and $\left(k^{e}, \ell^{e}\right)$ are the efficient allocations, and $r_{k}$ and $r_{l}$ are the equilibrium prices that support the efficient allocation as a competitive equilibrium. Table 5 reports the results for this counterfactual income compared with income inequality associated with actual agricultural output.

Not only farmers at the lower end of the productivity (and income) distribution benefit the most from the increase in the return to factors, but also overall inequality declines by more than 40 percent in terms of the variance of log agricultural income (from a variance of 1.7 to 1.0 in the counterfactual). More dramatic are the changes in income across the richest and poorest households. Whereas the ratio of income between farmers in the top and bottom quintiles is a factor of 35-fold in the actual allocation, the ratio falls to 5.9-fold in the counterfactual income associated with 
Table 5: Actual and Efficient Distributions of Land, Capital, Output, and Agricultural Income

\begin{tabular}{|c|c|c|c|c|c|c|}
\hline & \multicolumn{5}{|c|}{ Productivity Partition (Quintiles) } & \multirow{2}{*}{$\begin{array}{c}\text { var } \\
(\ln x)\end{array}$} \\
\hline & 1 st & 2 nd & $3 \mathrm{rd}$ & 4 th & 5 th & \\
\hline Farm productivity $\left(s_{i}\right)$ & 0.11 & 0.29 & 0.51 & 0.88 & 3.21 & 1.40 \\
\hline \multicolumn{7}{|l|}{ Land $\left(l_{i}\right)$} \\
\hline Actual & 0.80 & 0.83 & 0.90 & 1.00 & 1.46 & 0.66 \\
\hline Efficient & 0.00 & 0.01 & 0.03 & 0.11 & 4.85 & 6.62 \\
\hline \multicolumn{7}{|l|}{ Capital $\left(k_{i}\right)$} \\
\hline Actual & 0.97 & 1.00 & 0.97 & 0.92 & 1.15 & 1.08 \\
\hline Efficient & 0.00 & 0.01 & 0.03 & 0.11 & 4.85 & 6.62 \\
\hline \multicolumn{7}{|l|}{ Output $\left(y_{i}\right)$} \\
\hline Actual & 0.10 & 0.27 & 0.47 & 0.82 & 3.34 & 1.71 \\
\hline Efficient & 0.00 & 0.01 & 0.03 & 0.11 & 4.85 & 6.62 \\
\hline \multicolumn{7}{|l|}{ Agricultural income } \\
\hline Actual & 0.10 & 0.27 & 0.47 & 0.82 & 3.34 & 1.71 \\
\hline Counterfactual & 0.50 & 0.51 & 0.53 & 0.56 & 2.91 & 1.01 \\
\hline Ratio & 18.72 & 4.34 & 2.53 & 1.66 & 1.63 & - \\
\hline
\end{tabular}

Notes: Household farms are ranked by farm productivity $s_{i}$ and grouped in quitiles. Land, capital, output, and income are in per hours terms and normalized by their mean. Actual income is the sum/net of agricultural output and factor income/payments whereas counterfactual income is computed assuming actual allocations are the endowments and the efficient allocation is achieved via perfectly competitive rental markets. Ratio refers to counterfactual to actual agricultural income. Data for Malawi ISA 2010/11.

the efficient allocation, that is income inequality among these farmers falls by a factor of at least 6-fold. Moreover, while the ratio of efficient to actual income increases for all groups of household farms, the increase is larger and quite substantial for the poorest farmers, a 18.7-fold increase in agricultural income in the first quintile, suggesting the potential for poverty reduction associated with this hypothetical reform.

We conclude that well-functioning rental markets for capital and land to achieve the efficient allocation of operational scales can lead to substantial increases in agricultural productivity as well as important reductions in income inequality and poverty. 


\section{Conclusions}

There is substantial misallocation of land and other complementary factors in the agricultural sector in Africa. Using detailed nationally-representative household-farm level data for Malawi, we show that a reallocation of land (and capital) to their efficient use increases agricultural output and productivity by a factor of 2.82-fold. We show that this large gain in agricultural productivity in Malawi is not due to overly dispersed farm TFP compared with dispersion across establishments in other sectors or in more developed countries. Instead, the large output gain is due to severe factor misallocation. We find that land size (and capital) are essentially unrelated to farm TFP. This result is not entirely surprising given the egalitarian nature of land-use distributions irrespective of productivity and weak property rights over land in Malawi. Moreover, when using the available panel data to estimate household-farm fixed effects of productivity and inputs that control for time and transitory variations such as potential measurement error, the agricultural output gain is still quite substantial, between 1.7 to 2.0-fold. We show that reallocation gains remain substantial even when we consider alternative production parameters, more flexible technologies, and control for crop production differences.

Our assessment of misallocation focuses on the aggregate productivity cost associated with actual allocations, whereas in practice these allocations arise from institutions designed to deal with insurance or equity considerations. Clearly, these are relevant issues that must be considered more broadly. Nevertheless, regarding income inequality, we emphasize how equalizing inputs is not effective at equalizing agricultural incomes in this context since households are heterogeneous in their ability to generate income with the same inputs. We show that an efficient reallocation of inputs

can not only attain a large aggregate productivity gain, but also a large reduction in agricultural income inequality and poverty. The reason for these distributional gains is that the poorest agricultural households happen to be the least productive and hence benefit the most from secure property rights and the rental income associated with an efficient allocation. Our findings point to a press- 
ing need to facilitate the reallocation of land and other factors of production to more productive uses, which requires well-defined property rights over land and the development of well-functioning land and complementary markets. What policies and institutions are best in supporting a better allocation of resources in the agricultural sector is of crucial importance for future research.

We also emphasize that the increase in agricultural productivity from the efficient reallocation of factors would trigger of a profound process of structural transformation by which the agricultural sector in Malawi could approach levels of farm size and sectoral employment shares similar to that of industrialized countries (Adamopoulos and Restuccia, 2014). In this context, an important area for future research is the set of policies and institutions that would facilitate the movement of labor out of agriculture and into non-agricultural sectors in this process. Moreover, while our analysis takes farm productivity as given, it may also be of interest to assess the dynamic implications of misallocation. For instance, the situation where a reduction in misallocation would encourage productive farmers to grow by utilizing modern inputs (mechanization, chemical seeds, and other intermediate inputs) and by investing in better farm management practices (see Restuccia and Rogerson, 2017, for a discussion on the importance of the dynamic implications of misallocation). Similarly, while the gains from the reallocation of agricultural inputs across wives and husbands within farm households are relatively small (Udry, 1996) compared to the gains from reallocation across households that we find, the quantitative role of women - who are potentially more restricted in land (and capital) inputs than men in many parts of the world - in understanding productivity differences across farms remains an important open question. We leave these important extensions of our analysis for future research.

\section{References}

Adamopoulos, T., Brandt, L., Leight, J., and Restuccia, D. (2021). Misallocation, selection, and productivity: A quantitative analysis with micro data from China. Econometrica, forthcoming. 
Adamopoulos, T. and Restuccia, D. (2014). The Size Distribution of Farms and International Productivity Differences. American Economic Review, 104(6):1667-97.

Adamopoulos, T. and Restuccia, D. (2020). Land reform and productivity: A quantitative analysis with micro data. American Economic Journal: Macroeconomics, 12(3):1-39.

Aragón, F. M., Restuccia, D., and Rud, J. P. (2022). Assessing misallocation in agriculture: plots versus farms. Technical report, National Bureau of Economic Research.

Arthi, V., Beegle, K., De Weerdt, J., and Palacios-López, A. (2018). Not your average job: Measuring farm labor in Tanzania. Journal of Development Economics, 130:160-172.

Banerjee, A. V., Gertler, P. J., and Ghatak, M. (2002). Empowerment and efficiency: Tenancy reform in West Bengal. Journal of Political Economy, 110(2):239-280.

Beegle, K., Carletto, C., and Himelein, K. (2012). Reliability of Recall in Agricultural Data. Journal of Development Economics, 98(1):34-41.

Beg, S. (2022). Digitization and development: Property rights security, and land and labor markets. Journal of the European Economic Association, 20(1):395-429.

Bento, P. and Restuccia, D. (2017). Misallocation, establishment size, and productivity. American Economic Journal: Macroeconomics, 9(3):267-303.

Besley, T. (1995). Property Rights and Investment Incentives: Theory and Evidence from Ghana. Journal of Political Economy, 103(5):903-937.

Besley, T. and Ghatak, M. (2010). Property Rights and Economic Development, volume 5 of Handbook of Development Economics, chapter 0, pages 4525-4595. Elsevier.

Bick, A., Fuchs-Schundeln, N., and Lagakos, D. (2016). How do Average Hours Worked Vary with Development? Cross-Country Evidence and Implications. Working Paper 21874, National Bureau of Economic Research.

Binswanger, H. P. (1974). The measurement of technical change biases with many factors of production. American Economic Review, 64(6):964-976.

Bold, T., Kaizzi, K. C., Svensson, J., and Yanagizawa-Drott, D. (2015). Low quality, low returns, low adoption: Evidence from the market for fertilizer and hybrid seed in Uganda. Working Paper.

Buera, F. J., Kaboski, J. P., and Shin, Y. (2014). Macro-Perspective on Asset Grants Programs: Occupational and Wealth Mobility. American Economic Review, 104(5):159-64.

Carletto, C., Savastano, S., and Zezza, A. (2013). Fact or Artifact: The Impact of Measurement Errors on the Farm Size - Productivity Relationship. Journal of Development Economics, $103(\mathrm{C}): 254-261$.

Chari, A., Liu, E. M., Wang, S.-Y., and Wang, Y. (2021). Property rights, land misallocation, and agricultural efficiency in china. The Review of Economic Studies, 88(4):1831-1862. 
Chen, C. (2017). Untitled Land, Occupational Choice and Agricultural Productivity,. American Economic Journal: Macroeconomics, 9(4):91-121.

Chen, C. (2020). Technology adoption, capital deepening, and international productivity differences. Journal of Development Economics, 143:102388.

Chen, C., Restuccia, D., and Santaeulalia-Llopis, R. (2021). The effects of land markets on resource allocation and agricultural productivity. Review of Economic Dynamics, forthcoming.

de Magalhães, L., Koh, D., and Santaeulàlia-Llopis, R. (2019). The costs of consumption smoothing: less schooling and less nutrition. Journal of Demographic Economics, 85(3):181-208.

de Magalhães, L. and Santaeulàlia-Llopis, R. (2018). The consumption, income, and wealth of the poorest: An empirical analysis of economic inequality in rural and urban sub-saharan africa for macroeconomists. Journal of Development Economics, 134:350-371.

de Nicola, F. and Giné, X. (2014). How accurate are recall data? evidence from coastal India. Journal of Development Economics, 106:52-65.

de Soto, H. (2000). The Mystery of Capital: Why Capitalism Triumphs in the West and Fails Everywhere Else. Basic Books. New York.

Deaton, A. (1997). The Analysis of Household Surveys. A Microeconometric Approach to Development Policy. The Johns Hopkins University Press.

Deininger, K., Carletto, C., Savastano, S., and Muwonge, J. (2012). Can diaries help in improving agricultural production statistics? evidence from Uganda. Journal of Development Economics, 98(1):42-50.

Desiere, S. and Jolliffe, D. (2018). Land productivity and plot size: Is measurement error driving the inverse relationship? Journal of Development Economics, 130:84-98.

Donovan, K. (2021). The equilibrium impact of agricultural risk on intermediate inputs and aggregate productivity. The Review of Economic Studies, 88(5):2275-2307.

Foster, A. D. and Rosenzweig, M. R. (2011). Are Indian Farms Too Small? Mechanization, Agency Costs, and Farm Efficiency. Unpublished Manuscript, Brown University and Yale University.

Gollin, D., Lagakos, D., and Waugh, M. E. (2014). Agricultural Productivity Differences across Countries. American Economic Review, 104(5):165-70.

Gollin, D., Parente, S., and Rogerson, R. (2002). The Role of Agriculture in Development. American Economic Review, 92(2):160-164.

Gottlieb, C. and Grobovsek, J. (2019). Communal land and agricultural productivity. Journal of Development Economics, 138:135-152.

Hopenhayn, H. A. (2014). Firms, misallocation, and aggregate productivity: A review. Annual Review of Economics. 
Hsieh, C.-T. and Klenow, P. J. (2009). Misallocation and Manufacturing TFP in China and India. The Quarterly Journal of Economics, 124(4):1403-1448.

Kishindo, P. (2011). The Village Head and the Problem of Role Relevance in the Context of Declining Rural Land Availability in Malawi. Working Papers 2, Centre for Social Research, Chancellor College, Zomba, Malawi.

Larson, D. F., Otsuka, K., Matsumoto, T., and Kilic, T. (2014). Should African Rural Development Strategies Depend on Smallholder Farms? An Exploration of the Inverse-Productivity Hypothesis. Agricultural Economics, 45(3):355-367.

Lobell, D. B., Azzari, G., Burke, M., Gourlay, S., Jin, Z., Kilic, T., and Murray, S. (2020). Eyes in the sky, boots on the ground: Assessing satellite- and ground-based approaches to crop yield measurement and analysis. American Journal of Agricultural Economics, 102(1):202-219.

Midrigan, V. and Xu, D. Y. (2014). Finance and Misallocation: Evidence from Plant-Level Data. American Economic Review, 104(2):422-458.

Morris, B. (2016). An Environmental History of Southern Malawi: Land and People of the Shire Highlands.

Pachai, B. (1973). Land Policies in Malawi: An Examination of the Colonial Legacy. The Journal of African History, 14(4):681-698.

Restuccia, D. and Rogerson, R. (2008). Policy distortions and aggregate productivity with heterogeneous establishments. Review of Economic Dynamics, 11(4):707-720.

Restuccia, D. and Rogerson, R. (2017). The Causes and Costs of Misallocation. Journal of Economic Perspectives, 31(3):151-74.

Restuccia, D., Yang, D. T., and Zhu, X. (2008). Agriculture and Aggregate Productivity: A Quantitative Cross-Country Analysis. Journal of Monetary Economics, 55(2):234-250.

Santaeulàlia-Llopis, R. and Zheng, Y. (2018). The Price of Growth: Consumption Insurance in China 1989-2009. American Economic Journal: Macroeconomics, 10(4):1-35.

Shaban, R. A. (1987). Testing Between Competing Models of Sharecropping. Journal of Political Economy, pages 893-920.

Udry, C. (1996). Gender, Agricultural Production, and the Theory of the Household. Journal of Political Economy, 104(5):1010-46.

Valentinyi, A. and Herrendorf, B. (2008). Measuring Factor Income Shares at the Sector Level. Review of Economic Dynamics, 11(4):820-835.

Yang, M.-J. (2021). Micro-level misallocation and selection. American Economic Journal: Macroeconomics, 13(4):341-68. 


\section{Appendix}

\section{A Data}

The Malawi Integrated Survey of Agriculture (ISA) is part of a new generation of household surveys funded by the Bill \& Melinda Gates Foundation (BMGF) and led by the Living Standards Measurement Study (LSMS) Team in the Development Research Group (DECRG) of the World Bank to improve the quality and policy relevance of household-level data on agriculture in Sub-Saharan Africa. The Malawi ISA incorporates an extended and comprehensive agricultural questionnaire on agricultural production and factor inputs, including land quality and rain.

Land size and land quality. We measure household land as the sum of the size (in acres) of each household's plot used for cultivation. We include rented-in land in household land size. For the vast majority of plots, the acres per plot are recorded using GPS with precision of $1 \%$ of an acre. For the remaining plots, size is self-reported with an estimate from the household. This leaves virtually no room for error in our measure of land input, see a detailed assessment in Carletto et al. (2013). The data also contain detailed information on the quality of land for each plot used in each household. We consider all 11 dimensions of land quality available: elevation, slope, erosion, soil quality, nutrient availability, nutrient retention capacity, rooting conditions, oxygen availability to roots, excess salts, topicality, and workability. The slope (in \%) and elevation (in meters) are continuous variables while the rest of land quality variables are categorical such as terrain roughness (plains, lowlands, plateaus, hills, mountains), erosion (1 none, 2 low, 3 moderate, 4 high), nutrient availability, nutrient retention, rooting conditions, oxygen to roots, excess of salts, toxicity and workability (1 constraint, 2 moderate constraint, 3 severe constraint and 4 very severe constraint). These measures are largely from geographical information system such as the Harmonized World Soil Database.

Our benchmark land quality index is defined per household as the predicted value of output (net of rain effects which we discuss in the next Section) generated by the joint behavior of all dimensions of land quality controlling for capital and land size, see the first column in Table A-1. We also explore alternative definitions of the land quality index in Table A-1 that depend on the number of land quality dimensions that we incorporate and on the way we control for capital and land. A reassuring aspect of our land quality index, defined from physical measures (e.g., erosion, soil quality, etc.), is that it is positively related to land prices, see Table A-2. Finally, we perform a robustness analysis of our reallocation results with respect to our entire set of land quality indexes 
without substantial changes in our findings, see Table A-3.

Table A-1: Land Quality Index and Its Dimensions

\begin{tabular}{|c|c|c|c|c|c|c|}
\hline \multirow[b]{3}{*}{ Dimensions: } & \multicolumn{6}{|c|}{ Land Quality Index } \\
\hline & \multirow{2}{*}{$\begin{array}{c}\text { Benchmark } \\
q_{0} \\
\end{array}$} & \multicolumn{5}{|c|}{ Alternative Definitions } \\
\hline & & $q_{1}$ & $q_{2}$ & $q_{3}$ & $q_{4}$ & $q_{5}$ \\
\hline Elevation & $\checkmark$ & $\checkmark$ & $\checkmark$ & $\checkmark$ & $\checkmark$ & $\checkmark$ \\
\hline Slope & $\checkmark$ & $\checkmark$ & $\checkmark$ & $\checkmark$ & $\checkmark$ & $\checkmark$ \\
\hline Terrain roughness & $\checkmark$ & - & $\checkmark$ & - & $\checkmark$ & - \\
\hline Erosion & $\checkmark$ & - & $\checkmark$ & - & $\checkmark$ & - \\
\hline Nutritient availability & $\checkmark$ & - & $\checkmark$ & - & $\checkmark$ & - \\
\hline Nutritient retention & $\checkmark$ & - & $\checkmark$ & - & $\checkmark$ & - \\
\hline Rooting conditions & $\checkmark$ & - & $\checkmark$ & - & $\checkmark$ & - \\
\hline Oxygen to roots & $\checkmark$ & - & $\checkmark$ & - & $\checkmark$ & - \\
\hline Excess salts & $\checkmark$ & - & $\checkmark$ & - & $\checkmark$ & - \\
\hline Toxicity & $\checkmark$ & - & $\checkmark$ & - & $\checkmark$ & - \\
\hline Workability & $\checkmark$ & - & $\checkmark$ & - & $\checkmark$ & - \\
\hline \multicolumn{7}{|l|}{ Additional controls: } \\
\hline Capital & $\checkmark$ & $\checkmark$ & - & - & $\begin{array}{c}\checkmark \\
\text { (Const.) }\end{array}$ & $\begin{array}{c}\checkmark \\
\text { (Const.) }\end{array}$ \\
\hline Land size & $\checkmark$ & $\checkmark$ & - & - & $\begin{array}{c}\checkmark \\
\text { (Const.) }\end{array}$ & $\begin{array}{c}\checkmark \\
\text { (Const.) }\end{array}$ \\
\hline
\end{tabular}

Note: Summary definitions of different measures of land quality index. Our benchmark measure utilizes all 11 dimensions of land quality in addition to elevation and slope, controlling for capital and land size. For alternative measures $q_{4}$ and $q_{5}$, we control for capital and land size but restrict the coefficients to be identical to capital and land shares.

Rain. It is important to control for unanticipated temporary output shocks that can contribute to explain the variation in output and productivity across households in the data. Rain shocks are among the most important shocks in agriculture. We use the annual precipitation which is the total rainfall in millimetres $(\mathrm{mm})$ in the last 12 months. Our benchmark measure of output (value added) is net of the rain effects. Specifically, we group observations into 10 bins sorted by their observed level of rain, and then regress the $(\log )$ value added on rain deciles to net the effect of rain shocks. As rain might be more relevant in some months than others we also tried to control for an alternative measure of rain, the wettest quarter within the last 12 months. We find an output gain of 2.88 , similar to 2.82 in our baseline.

Labor. In Malawi, not only the household head but also a large proportion of the households members, which average 4.6 per household, contribute to agricultural work. The household head 
Table A-2: Land Quality Index and Land Price

\begin{tabular}{lccccccc}
\hline & \multicolumn{5}{c}{ Land Quality Index } \\
& Benchmark & \multicolumn{5}{c}{ Alternative Definitions } \\
& $q_{0}$ & $q_{1}$ & $q_{2}$ & $q_{3}$ & $q_{4}$ & $q_{5}$ \\
\hline Correlation with land price & 0.189 & 0.200 & 0.202 & 0.204 & 0.196 & 0.196 \\
\hline
\end{tabular}

Notes: Rank correlation between the land quality index $q$ and the price of land computed as the self-reported estimated land value (under the hypothetical scenario in which the owner sells the land). We separately calculate this correlation for our benchmark measure of land quality and 5 alternative measures of land quality defined in Table A-1. The correlation is significant at the one percent level for all land quality measures. Data from Malawi ISA $2010 / 11$.

Table A-3: Output Gain with Different Land Quality Indexes

\begin{tabular}{ccccccc}
\hline & Benchmark & \multicolumn{5}{c}{ Alternative Definitions } \\
& $q_{0}$ & $q_{1}$ & $q_{2}$ & $q_{3}$ & $q_{4}$ & $q_{5}$ \\
\hline Output gain & 2.82 & 2.84 & 2.83 & 2.84 & 2.82 & 2.84 \\
\hline
\end{tabular}

Notes: Output gain associated with our benchmark measure of land quality and 5 alternative measures of land quality defined in Table A-1. Data from Malawi ISA 2010/11.

is identified as the person who makes economic decisions in the household (e.g., use of production or transfers). We define household members as individuals that have lived in the household at least 9 months in the last 12 months. These household members potentially include family (e.g. children, spouses, siblings, and parents) and also non-relatives (e.g. lodgers and servants). Individual information about each household member's (including children) extensive and intensive margins of labor supply is collected: (i) weeks worked, (ii) days per week, and (iii) hours per day, by plot and by agricultural activities covering the entire agricultural production. For the hired labor and free/exchange labor, we also observe number of days worked by men, women and children by plot and activities. The detailed information on individual agricultural labor days through the entire year avoids the seasonal component of labor supply; that is, we do not rely on data on labor supply related to 'last week/month' behavior. Our benchmark measure of household labor supply is aggregate days of all individuals (household members and non-members) supplied in all plots cultivated by the household in the rainy season. To control for human capital, i.e., the fact that not all hours might contribute the same to agricultural production, we construct household efficiency units by weighting individual hours using the wages of hired labor by age and sex groups as weights. We find that our results are robust to this alternative specification.

Capital equipment and structures. Agricultural capital equipment includes implements (i.e., hand 
hoe, slasher, axe, sprayer, panga knife, sickle, treadle pump and watering can) and machinery (e.g. ox cart, ox plough, tractor, tractor plough, ridger, cultivator, generator, motorized pump, grain mill, and others). Agricultural capital structures includes chicken houses, livestock kraals, poultry kraals, storage houses, granaries, barns, pig sties, etc. To measure the capital stock per item we use the estimated current selling price of capital items after conditioning on its use. We construct the household agricultural capital stock by aggregating across all agricultural items. The use of the selling price (not available in previous LSMS data) avoids the cumbersome perpetual inventory method adjustment for the age of capital to impute current value from the value at the time of purchase which requires recalling and depreciation assumptions by asset's age. We note that we observe a small set of farmers who have zero measured capital but report cultivated land and positive production. This may be because the data do not record a common set of very small tools and structures used by farmers. We hence follow Adamopoulos et al. (2021) and impute an amount of capital to all farms representing the value of this set of small tools and structures, with the value equal to $10 \%$ of the median of the calculated capital value.

Trimming strategy. The cost of misallocation summarized by the output gain is known to be sensitive to extreme values of inputs and outputs. We trim our sample to exclude apparent extreme values. Specifically, we trim the top and bottom $0.5 \%$ of each of output, land, capital, and estimated farm TFP. This trimming strategy substantially reduces measured dispersion of farm TFP by between 9 to 16 percent: the variance of log farm TFP shrinks from 1.67 to 1.40 in the 2010/11 cross-section and from 0.96 to 0.87 in the panel sample. In the context of the misallocation literature, trimming is also potentially a conservative strategy if high productivity units should in fact be allocated more inputs.

\section{B Measurement Error and Misallocation}

We assess the extent to which our results may be affected by measurement error through two approaches. First, we explore the panel dimension of the data to estimate household-farm fixed effects of productivity and inputs that abstract from time and transitory variation, including potential measurement error. Second, we explore additional counterfactual experiments to provide bounds on the relevance of measurement error for output gains. 


\section{B.1 Patterns of Misallocation with Panel Data}

Recall that the patterns of misallocation illustrated in Figure 1 are characterized with the 2010/11 wave of cross-sectional data. We note that these patterns remain remarkably similar if we instead use the panel sample. Figure A-1 illustrates the patterns using the panel data to estimate a householdfarm fixed effect of productivity. The correlation of farm productivity and inputs are very similar in the cross-section and panel data, for instance, the log correlation of land input and productivity is 0.17 in the cross-section and 0.21 in the panel, and similarly the log correlation of capital and productivity is 0.02 in the cross-section and also 0.02 in the panel.

\section{B.2 Recall Bias for Agricultural Production and Labor Input}

In rural settings the underreporting of agricultural production is a recurrent issue for survey data (Deaton, 1997; de Magalhães and Santaeulàlia-Llopis, 2018). There are two aspects of the Malawi ISA design that help mitigate and study this issue. First, in many instances the survey provides internal consistency checks (e.g., households are asked total sales, and also sales by crop and by plot; the interviewer must check in situ that the two sums coincide or otherwise re-interview). Second, the ISA collects data not only on agricultural production but also on consumption that includes food consumption (in physical units) from own production. This provides a unique opportunity to externally validate agricultural production using consumption data. In this context, a reassuring result is that in rural household-farms that do not sell their agricultural production and have little or no consumption purchases (i.e., about $50 \%$ of the entire rural sample), the reported agricultural production and the reported consumption net of transfers imply very similar quantities, which suggests a small scope for measurement error (from recall or elsewhere) in agricultural production, see de Magalhães and Santaeulàlia-Llopis (2018).

Not only agricultural production is collected retrospectively, but also labor input. To further investigate the basis for potential recall bias in the collection of production and labor input, we note that in Malawi there is only one main harvest associated with the only rainy season. We then re-conduct our entire analysis for only the households farms that are surveyed shortly (i.e., within four months) after harvest, the output gain is 2.78-fold which is only slightly lower than the 2.82-fold output gain in our benchmark specification. This finding suggests that our results are robust to recall bias. 


\section{Figure A-1: Patterns of Misallocation: Panel Specification}

(a) Land Size vs. Farm Productivity

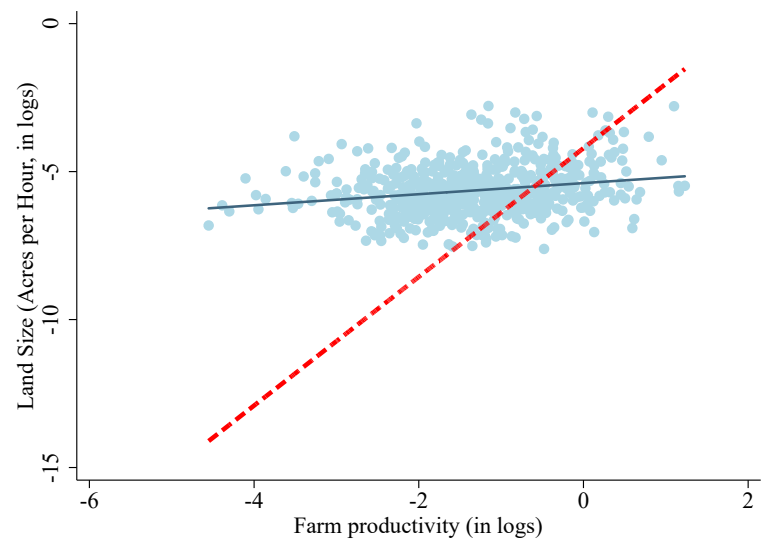

(c) Capital vs. Farm Productivity

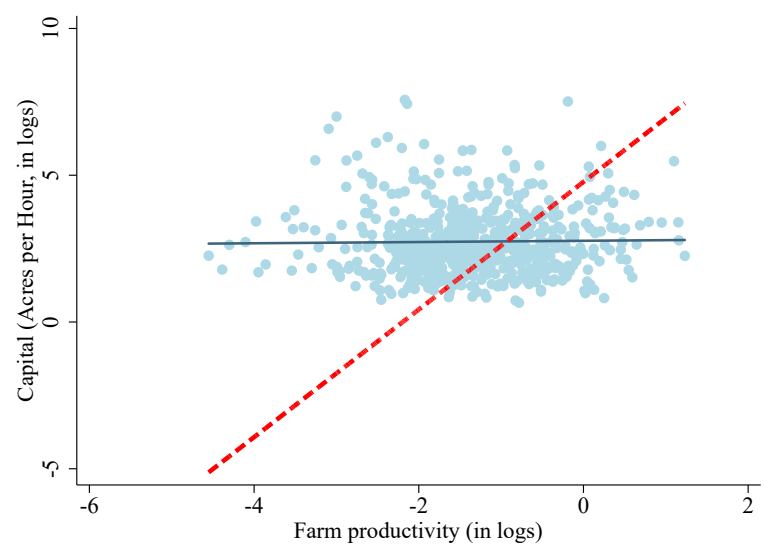

(b) MPL vs. Farm Productivity

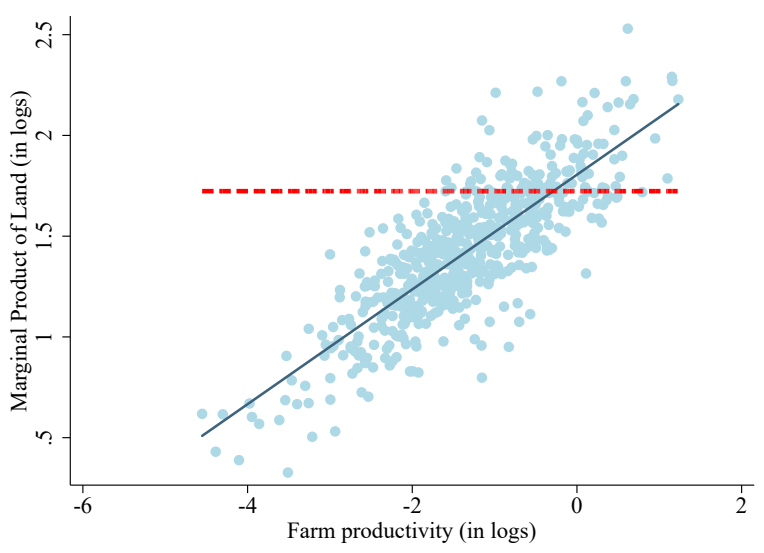

(d) MPK vs. Farm Productivity

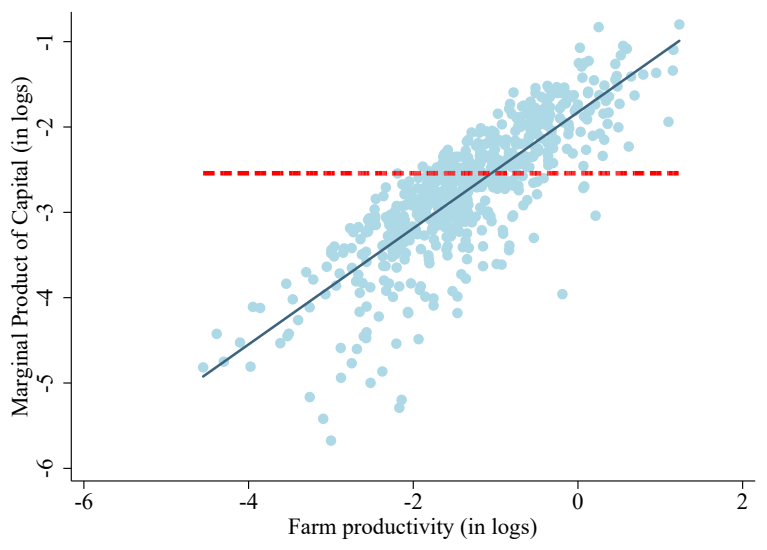

Notes: Panel (a) reports actual and efficient land operational size in farms $\ell_{i}$ with respect to farm productivity $s_{i}$. Panel (b) reports actual and efficient marginal product of land (MPL) with respect to farm productivity $s_{i}$. Panel (c) reports actual and efficient capital in farms $k_{i}$ with respect to farm productivity $s_{i}$. Panel (d) reports actual and efficient marginal product of capital (MPK) with respect to farm productivity $s_{i}$. Each (blue) dot represents a household farm in the data whereas the (red) dashed line represents the efficient allocation. Farm productivity is the household-farm fixed effect while farm inputs are from the 2010/11 wave. All variables have been logged. 


\section{B.3 Bounds of Output Gains}

We design the following experiment to better understand the nature of the output gain. Suppose a planner allocates the observed input sets $\left\{k_{i}\right\}$ and $\left\{l_{i}\right\}$ to farmers in a particular fashion, holding farm-level TFP unchanged, how large are the gains from reallocation? In other words, in this experiment, we hold the marginal distributions of $\left\{k_{i}\right\},\left\{l_{i}\right\}$, and $\left\{s_{i}\right\}$ constant but we allow for, for instance, assigning $l_{i}$ to an arbitrary farmer $j$.

The assignment with lowest possible output gain is positive assortative matching between inputs and farm productivity, which yields an output gain of 1.35-fold. The highest possible output gain is then obtained with negative assortative matching, which is 5.38-fold. Random assignment, which

means $\left\{k_{i}, \ell_{i}\right\}$ are uncorrelated with $\left\{s_{i}\right\}$, yields an output gain of around 3.1-fold. Note that with finite sample (7,505 observations) the output gain associated with this random assignment varies with the particular draw of random numbers. This comparison highlights the importance of the correlation. Our baseline output gain, 2.82-fold, is not much lower than that of random assignment. This is exactly because in our data, the correlation between inputs and farm productivity is very low, as documented in Figure 1.

\section{B.4 A Structural Interpretation of Measurement Error}

We estimate a structural model of measurement error to assess their potential importance in our quantitative results. We denote true capital, land, and output as $k_{i}, \ell_{i}$, and $y_{i}$. Capital and land inputs are functions of true productivity $z_{i}$ :

$$
\ln \left(k_{i}\right)=\zeta^{k} \ln \left(z_{i}\right)+d_{i}^{k}, \quad \ln \left(\ell_{i}\right)=\zeta_{\ell} \ln \left(z_{i}\right)+d_{i}^{\ell}
$$

An efficient allocation implies $\zeta^{k}=\zeta^{\ell}=1$ and $d_{i}^{k}=d_{i}^{\ell}=0$. Hence $\zeta^{k} \neq 1$ and $\zeta^{\ell} \neq 1$ indicate correlated distortions as in Bento and Restuccia (2017), while $d_{i}^{k} \neq 0$ and $d_{i}^{\ell} \neq 0$ indicate nonsystematic distortions.

We assume that variables (inputs and outputs) may be observed with error, i.e.,

$$
\begin{aligned}
& \ln \left(\tilde{k}_{i}\right)=\ln \left(k_{i}\right)+\varepsilon_{i}^{k}=\zeta^{k} \ln \left(z_{i}\right)+d_{i}^{k}+\varepsilon_{i}^{k}, \\
& \ln \left(\tilde{\ell}_{i}\right)=\ln \left(\ell_{i}\right)+\varepsilon_{i}^{\ell}=\zeta^{\ell} \ln \left(z_{i}\right)+d_{i}^{\ell}+\varepsilon_{i}^{\ell}, \\
& \ln \left(\tilde{y}_{i}\right)=\ln \left(y_{i}\right)+\varepsilon_{i}^{y},
\end{aligned}
$$


where $\varepsilon^{k}, \varepsilon^{\ell}$, and $\varepsilon^{y}$ represent (log) additive measurement error. The estimated farm productivity $\tilde{z}_{i}$ is then

$$
\tilde{z}_{i}=\frac{\tilde{y}_{i}}{\left(\tilde{k}_{i}^{\alpha} \tilde{\ell}_{i}^{1-\alpha_{i}}\right)^{\gamma}}=z_{i} \frac{\exp \left(\varepsilon_{i}^{y}\right)}{\left(\exp \left(\varepsilon_{i}^{k}\right)^{\alpha} \exp \left(\varepsilon_{i}^{\ell}\right)^{1-\alpha}\right)^{\gamma}}
$$

We now contrast the output gain calculated from observed variables with that calculated from true variables. Note that real aggregate inputs and output are identical to observed ones since measurement errors are mean zero. The true output gain from reallocating resources is

$$
e=\frac{Y^{e}}{Y^{a}}=\frac{\left(\sum_{i} z_{i}\right)^{1-\gamma}\left(K^{\alpha} L^{1-\alpha}\right)^{\gamma}}{\sum_{i} z_{i}^{1-\gamma}\left(k_{i}^{\alpha} \ell_{i}^{1-\alpha}\right)^{\gamma}}
$$

while the measured output gain is

$$
\tilde{e}=\frac{\tilde{Y}^{e}}{\tilde{Y}^{a}}=\frac{\left(\sum_{i} \tilde{z}_{i}\right)^{1-\gamma}\left(K^{\alpha} L^{1-\alpha}\right)^{\gamma}}{\sum_{i} \tilde{z}_{i}^{1-\gamma}\left(\tilde{k}_{i}^{\alpha} \tilde{\ell}_{i}^{1-\alpha}\right)^{\gamma}} .
$$

To structurally estimate this framework, we make the parametric assumption that $\varepsilon^{k}, \varepsilon^{\ell}$, and $\varepsilon^{y}$ are all normally distributed with variance $\sigma_{m}^{2}$. The parameter $\sigma_{m}^{2}$ governs the precision in measurement and we assume that additive measurement error is of the same magnitude for all inputs and outputs. In addition, we assume $d^{k}$ and $d^{\ell}$, the idiosyncratic distortions, follow normal distributions with variance $\sigma_{k}^{2}$ and $\sigma_{\ell}^{2}$, and true productivity follows a normal distribution with variance $\sigma_{s}^{2}$.

We use this framework to answer the following question: If true output gain $e$ is only half of measured output gain $\tilde{e}$, what is the implied magnitude of measurement error? We estimate this framework, which consists of six parameters: $\left\{\sigma_{k}^{2}, \sigma_{\ell}^{2}, \sigma_{m}^{2}, \zeta^{k}, \zeta^{\ell}, \sigma_{s}^{2}\right\}$, to match the following five moments from Malawi micro data: the variances of observed capital and labor input, the correlations between farm productivity and capital/labor input, and the measured output gain. We also use the fact that true output gain $e$ is half the measured output gain as our sixth moment to restrict the value of $\sigma_{m}^{2}$.

Considering our most conservative output gain associated with the fixed effects of inputs and productivity in the panel of 1.67-fold, half of this level renders a "true" output gain of 1.34-fold. We find that the magnitude of the measurement error must be huge, the estimated $\sigma_{m}^{2}=0.22$ and as a result, the variance of $(\log )$ observed land input $\tilde{\ell}_{i}$ must be almost two times larger than $(\log )$ true land input $\ell_{i}$, and the variance of (log) observed capital input $\tilde{k}_{i}$ must be $70 \%$ larger than (log) true capital input $k_{i}$. Given that our measure of land input is cultivated land at the household level measured via GPS, we think this magnitude of measurement error is unlikely, but nevertheless 
our analysis helps frame the extent to which remaining measurement error may be driving reported reallocation gains. 